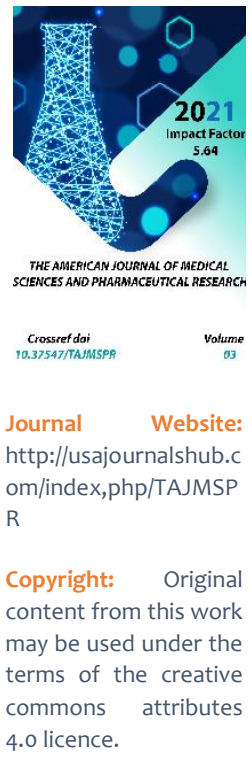

\title{
Predictors Of The Development Of Chronic Kidney Disease In Patients With Chronic Obstructive Pulmonary Disease
}

\author{
Kayumova Gulnoz Karimovna \\ Bukhara State Medical Institute, Uzbekistan \\ Akhmedova Nilufar Sharipovna \\ Bukhara State Medical Institute, Uzbekistan \\ Umurova Nigora Mavlyanovna \\ Bukhara State Medical Institute, Uzbekistan
}

\section{ABSTRACT}

The aim of the study was to identify predictors of decreased glomerular filtration in patients with chronic obstructive pulmonary disease (COPD). Materials and methods. We analyzed 145 case histories of patients diagnosed with COPD. The majority $(84.1 \%, \mathrm{n}=122)$ of them are males (the average age of men is $60.7 \pm 0.9$ years, the average age of women is $62.0 \pm 2.7$ years). A comparative analysis of the prevalence of risk factors for chronic kidney disease (CKD) in patients with COPD: age, gender, smoking, arterial hypertension, overweight, etc. The glomerular filtration rate (GFR) was calculated using the Chronic Kidney Disease Epidemiology Collaboration (CKD - EPI) formula, according to which the patients were divided into 6 groups: group 1 - hyperfiltration, group 2 - GFR CKD - EPI $\geq 90 \mathrm{ml} / \mathrm{min}$ / 1, $73 \mathrm{m2}$, 3rd - GFR CKD - EPI 60-89 ml / $\mathrm{min} / 1.73 \mathrm{m2}$, 4th - GFR CKD - EPI 45-59 ml / $\mathrm{min} / 1.73 \mathrm{m2}$, 5th - GFR CKD - EPI $30-44 \mathrm{ml} / \mathrm{min} / 1.73 \mathrm{mz}$ and 6th-GFR CKD-EPI <30 ml / min / $1.73 \mathrm{m2}$. Results. Patients with COPD have a high incidence of CKD risk factors. A correlation was found between the prevalence of CKD risk factors and the severity of COPD. The main predictors of the development of CKD in patients with COPD: duration of COPD $>9$ years, body mass index $>26.5 \mathrm{~kg} / \mathrm{m} 2$, smoking index> 51.3 , albumin $>44.0 \mathrm{~g} / \mathrm{l}$, total protein $>70.0 \mathrm{~g} / \mathrm{L}$, forced expiratory volume in the first second $\leq 1.6 \mathrm{~L}$, right atrial size $>35.5 \mathrm{~mm}$, systolic pressure in the pulmonary artery> $36.6 \mathrm{~mm} \mathrm{Hg}$. Art., the thickness of the posterior wall of the left ventricle $>10.5 \mathrm{~mm}$, Tiffno's index $\leq 62 \%$. Conclusion. It was found that patients with COPD have a high incidence of both traditional and nonspecific risk factors for a decrease in GFR.

\section{KEYWORDS}

Chronic obstructive pulmonary disease, chronic kidney disease, risk factors, cardiorenal continuum, cluster approach, predictive diagnostics, hypoxia, glomerular filtration rate, comorbidity, bronchial obstruction. 


\section{INTRODUCTION}

In the current conditions of the "popularity" of the topic of comorbidity, most therapeutic scientific schools consider specific nosologies, including chronic obstructive pulmonary disease (COPD), in close connection with other common socially significant diseases [1-7], one of which is chronic kidney disease (CKD). CKD occupies a special place among chronic noncommunicable diseases, since it is widespread, associated with a sharp deterioration in the quality of life, high mortality and (in the terminal stage) leads to the need to use expensive methods of substitution therapy [8]. The currently available concept of risk factors (RF) for the development and progression of CKD almost completely coincides with those in COPD [8, 9]. COPD is a disease of the respiratory tract with proven systemic effects such as hypoxemia, chronic inflammation, oxidative stress and, as a consequence, endothelial dysfunction [9, 10]. In addition, most of the systemic manifestations of COPD, such as anemia, depression, mineral bone disorders, cardiovascular complications, coincide with the manifestations of CKD and can be mistakenly regarded solely as manifestations of COPD [10-13]. The search for effective methods for the prevention and treatment of conditions with a polymorbid background is one of the most important medical and social problems due to the increase in the life expectancy of the population and the accumulation of patients with concomitant diseases in the population. The search for the most informative predictors of the risk of glomerular dysfunction in COPD is recognized as relevant, the identification of which at early stages should be attributed to the issues of predictive diagnosis.

The aim of this work is to identify predictors of decreased glomerular filtration in patients with COPD.

\section{MATERIALS AND METHODS}

We analyzed 145 case histories of inpatients with a verified diagnosis of grade I - IV COPD in accordance with the criteria for CKD $[8,18]$. The majority $(84.1 \%, n=122)$ were males $(p<0.001)$ (mean age $60.7 \pm 0.9$ years), in every 6 th observation women were included in the study $(15.8 \%, n=23)$ (mean age 62.0 \pm 2.7 years) $(p=$ $0.585)$. COPD was diagnosed in accordance with the recommendations of the Global Initiative for Chronic Obstructive Lung Disease (GOLD) [14]. The distribution of patients was carried out by age categories, taking into account the classification of the World Health Organization: 18-44 years - young age, 45-59 years - middle age, 60-74 years - elderly age, 75-89 years - old age [15].

A comparative analysis of the prevalence of RF for the development and progression of CKD in patients with COPD: age, sex, smoking, arterial hypertension $(\mathrm{AH})$, disorders of carbohydrate metabolism, overweight, including obesity, etc. , diabetes mellitus (DM), pathology of the urinary system (UCS)), which have a significant impact on the prognosis for patients [16]. All patients performed the calculation of the glomerular filtration rate (GFR) according to the formula Chronic Kidney Disease Epidemiology Collaboration (CKD - EPI) 2009 as amended in 2011. The calculation was carried out on the basis of serum creatinine levels, for women with creatinine levels $\leq 0.7 \mathrm{mg} / 100 \mathrm{ml}$ by formula

$144 \times(0.993)$ Age $\times(\mathrm{SCr} / 0.7) 0.328$,

with a creatinine level> $0.7 \mathrm{mg} / 100 \mathrm{ml}$ -

$144 \times(0.993)$ Age $\times(\mathrm{SCr} / 0.7) 1.210$;

for men with creatinine levels $\leq 0.9 \mathrm{mg} / 100 \mathrm{ml}$ according to the formula

$141 \times(0.993)$ Age $\times($ SCy / 0.9) -0.412 , 
at a creatinine level> $0.9 \mathrm{mg} / 100 \mathrm{ml}$ according to the formula

$141 \times(0.993)$ Age $\times(\mathrm{SCr} / 0.9)-1.210[8,17]$.

According to the GFR value CKD - EPI, patients with COPD were divided into 6 groups: group 1 included patients with hyperfiltration, group 2 - with GFR CKD - EPI $\geq 90 \mathrm{ml} / \mathrm{min} / 1.73 \mathrm{m2}$, group 3 - with GFR CKD -EPI 60-89 $\mathrm{ml} / \mathrm{min} /$ $1.73 \mathrm{m2}$, in the 4th - with GFR CKD - EPI 45-59 $\mathrm{ml} / \mathrm{min} / 1.73 \mathrm{m2}$, in the 5 th - with GFR CKD $\mathrm{EPI} 30-44 \mathrm{ml} / \mathrm{min} / 1.73 \mathrm{~m} 2$ and in the 6th - with GFR CKD - EPI $<30 \mathrm{ml} / \mathrm{min} / 1.73 \mathrm{mz}$.

The work was carried out taking into account the requirements of biomedical ethics, the protocol and study design were approved by the ethics committee.

Statistical research methods included a Microsoft Excel spreadsheet package, statistical calculations using the IBM SPSS Statistics 22 software package. To assess intergroup differences, Student's t-test was used. Data are presented as arithmetic mean (M) \pm standard deviation. When analyzing contingency tables, the Pearson $\chi^{2}$ test was used. The analysis of the relationship of variables was carried out by the method of Pearson's linear correlation analysis ( $r$ ) and Spearman's rank correlation ( $r s$ ). Differences were considered significant at $p<0.05$. Clusters of RF for GFR decrease in patients with COPD were determined using multivariate analysis: cluster analysis by methods of constructing classification trees and K-means, factor analysis by the method of principal components.

\section{RESULTS AND DISCUSSION}

The optimal level of GFR CKD - EPI in the range of $90-110 \mathrm{ml} / \mathrm{min} / 1.73 \mathrm{mz}$ had every 5 th observed ( $n=28 ; 19.3 \%$ of patients). The study cohort was dominated by patients with a moderate decrease in GFR CKD - EPI 60-89 ml
/ $\min / 1.73 \mathrm{~m} 2$ ( $\mathrm{n}=77 ; 53.1 \%$ of patients). This GFR, according to the available recommendations, corresponds to the CKD stage $\mathrm{C} 2$ and is considered the age norm "for the elderly, whose proportion in the sample was $58.6 \%(n=85)$ and is typical for patients with COPD [8, 14, 18]. Hyperfiltration was detected in $4.1 \%$ of patients $(n=6)$, a decrease in GFR CKD - EPI within 45-59 ml / $\mathrm{min} / 1.73 \mathrm{m2}$ - in $13.1 \%(n=19)$. According to the 2012 National Recommendations, this group has the highest cardiovascular risk, 2 or more times higher than that with a GFR of $60-89 \mathrm{ml} / \mathrm{min} / 1.73 \mathrm{mz}$ [13, 18]. The prevalence of patients with severe and extremely severe COPD in this group indicates the important role of chronic hypoxia in the development of the pathological process [14, 18]. Each 10th patient had a GFR CKD-EPI 30-44 $\mathrm{ml} / \mathrm{min} / 1.73 \mathrm{mz}$ ( $\mathrm{n}=12 ; 8.2 \%$ of patients), GFR CKD-EPI $<30 \mathrm{ml} / \mathrm{min} / 1.73 \mathrm{mz}$ - in 2, 06\% of patients $(n=3)$.

In all groups, men predominated, which is associated with the peculiarity of the epidemiology of COPD $[14,18]$ : in the $15 t-100 \%$, in the 2 nd $-85.7 \%$, in the $3 \mathrm{rd}-81.8 \%$, in the 4 th $89.4 \%$, in the 5 th $-83.3 \%$ and in the 6 th $-66.6 \%$ of patients $(p<0.05)$. The largest proportion was made up of elderly people $-58.6 \%(n=85)$ $(p=0.110)$. The number of elderly men with COPD was $59.0 \%(n=72)$, women - $31.2 \%(n=7)$. Each 2nd patient over 60 years old $(p=0.278)$ had GFR $\leq 60 \mathrm{ml} / \mathrm{min} / 1.73 \mathrm{mz}$. A negative correlation was found between age and GFR CKD - EPI $(r=-0.426 ; p<0.05)$.

Overweight and obesity were registered in every second patient ( $n=72 ; 49.6 \%$ ) in the sample ( $p=0.973)$, which slightly exceeds the general population studies (30-35\%) [19]. The average value of the body mass index (BMI) in the cohort of the surveyed corresponded to overweight, amounting to $26.6 \pm 0.6 \mathrm{~kg} / \mathrm{m} 2$. $\mathrm{BMI}$ was higher in the group with GFR CKD $\mathrm{EPI}<30 \mathrm{ml} / \mathrm{min} / 1.73 \mathrm{mz}(\mathrm{p}=0.05)$. 
The prevalence of hypertension among patients with COPD was $59.3 \%(n=86 ; p=$ $0.083)$. Despite the fact that the incidence of comorbid cardiovascular pathology was comparable at different GFR values CKD-EPI, the registration of hypertension (68.4\%) in the group of patients with GFR CKD-EPI $45-59 \mathrm{ml} /$ min / $1.73 \mathrm{~m} 2$ was significantly higher than in the group of patients with COPD without renal impairment (from 23.0 to $43.6 \%$, depending on the severity of COPD according to the literature) [19].

Probably, smoking plays an important role in the occurrence of glomerular hypofiltration in patients with COPD, a common RF for COPD and CKD, the prevalence of which was $79.3 \%$ ( $\mathrm{n}$ = 115; $\mathrm{p}$ <0.001). The smoker's index (ICI) was highest in the group with GFR CKD - EPI 30-44 $\mathrm{ml} / \mathrm{min} / 1.73 \mathrm{m2}$ and correlated with the severity of COPD $(p<0.05)$.

The creatinine level in the sample was $95.9 \pm$ $2.8 \mu \mathrm{mol} / \mathrm{L}$. A creatinine index $\geq 90 \mu \mathrm{mol} / \mathrm{L}$ was found in $55.1 \%$ of patients $(n=80)$. The mean value of forced expiratory volume in 1 second (FEV1) in the cohort of COPD patients was $45.1 \pm 1.8 \%: 43$ men, $8 \pm 1.9 \%$, women $51.5 \pm$ 4.8\% ( $p=0.114) ; 1.6 \pm 0.2 \mathrm{~L}:$ men $1.7 \pm 0.3 \mathrm{~L}$, women $1.0 \pm 0.1 \mathrm{~L}(p=0.315)$. FEV1 and Tiffno's index were lower in the CKD - EPI groups within 90-110 ml / $\mathrm{min} / 1.73 \mathrm{m2}$, CKD - EPI GFR 60-89 ml / $\min / 1.73 \mathrm{m2}$, CKD - EPI GFR within $45-59 \mathrm{ml} / \mathrm{min} / 1.73 \mathrm{m2}$, GFR CKD-EPI $30-44 \mathrm{ml}$ $/ \mathrm{min} / 1.73 \mathrm{~m} 2$ than in the group of patients with hyperfiltration $(p<0.05)$.

The majority of patients with COPD (25-60\%) develop protein-energy malnutrition up to "pulmonary cachexia" [20, 21]. In such patients, there is a greater degree of manifestations of systemic inflammation and nutritional deficiency. This is expressed in higher concentrations of interleukin 6 (IL-6), a more significant increase in adiponectin content and a deterioration in nutritional status indicators, namely, a decrease in body mass index, lean body mass, and the amount of skin and fatty tissue. Due to the loss of muscle tissue, the level of serum creatinine naturally decreases, which directly depends on it [7]. The syndrome of hypermetabolismhypercatabolism, manifested by increased breakdown of tissue proteins and increased consumption of carbohydrate-lipid reserves and is closely associated with systemic inflammatory response, metabolic acidosis, imbalance of hormones with anabolic action, is the result of a systemic inflammatory response and is diagnosed on average in half of patients with CKD. Protein catabolism and a decrease in muscle mass are also facilitated by the imbalance of hormones with an anabolic effect that develops in CKD - increased secretion of parathyroid hormone, resistance to growth hormone, androgen deficiency, suppression of growth factor 1 inhibitor. Uremic toxins, some of which are anorexigens, and most of which are products of protein metabolism, have a negative effect, ranging from oxidative stress to endothelial dysfunction, impaired nitric oxide synthesis, the development of interstitial renal fibrosis, sarcopenia, increased proteinuria and a negative effect on the rate of progression of CKD [13, 22]. In such a situation, a contradiction arises between the need to maintain an adequate nutritional status in patients with COPD in combination with CKD against the background of emerging or already existing protein-energy malnutrition and the need to limit protein intake in order to slow the progression of renal failure. It has been established that a strict low-protein diet in combination with keto analogs of essential amino acids allows various ways to reduce traditional and non-traditional RF and the progression of CKD, COPD and cardiovascular diseases in comorbid patients [13]. The finding of a negative correlation between CKD-EPI GFR and the level of albumin $(r=-0.268 ; p<0.05)$ and alpha-1-globulin $(r=-0.334 ; p<0.05)$ in the 
study confirms the well-known mechanisms of CKD development in high-protein diet and hypercatabolic syndrome.

A negative correlation was found between GFR $C K D$ - EPI and the thickness of the posterior wall of the left ventricle (LVDV) $(r=-0.356 ; p$ $<0.05)$. Also, a positive correlation was found between the level of creatinine and LVTD $(r=$ $0.334 ; p<0.05)$. It was found that with a decrease in glomerular filtration, left ventricular hypertrophy increases $(p<0.001)$, which is probably due to pathogenetic mechanisms (an increase in circulating blood volume, activation of the renin-angiotensinaldosterone system and an increase in pre- and afterload in CKD). These dependences can be explained within the framework of the "cardiorenal continuum" [23]. According to multivariate analysis, the main predictors of a decrease in GFR in patients with COPD were identified: COPD duration> 9 years, BMI> 26.5 $\mathrm{kg} / \mathrm{m} 2, \mathrm{ICl}>51.3$, blood albumin $>44 \mathrm{~g} / \mathrm{L}$, total protein level $>70 \mathrm{~g} / \mathrm{l}, \mathrm{FEV} 1 \leq 1.6 \mathrm{l}, \mathrm{TZSLZH}>10.5$ $\mathrm{mm}$, Tiffno index $\leq 62 \%$.

\section{CONCLUSION}

Early diagnosis of CKD in COPD remains relevant, which is difficult due to the commonality of both RF and systemic manifestations. It has been established that patients with COPD have a high incidence of RF of CKD. Hypofiltration in COPD is facilitated by: COPD duration> 9 years, $\mathrm{BMI}>26.5 \mathrm{~kg} / \mathrm{m} 2, \mathrm{ICl}>$ 51.3, albumin $>44 \mathrm{~g} / \mathrm{L}$, total protein $>70 \mathrm{~g} / \mathrm{L}$, FEV $1 \leq 1.6 \mathrm{~L}$, LVTDV $>10.5 \mathrm{~mm}$, Tiffneau index $\leq$ $62 \%$.

\section{REFERENCES}

1. Chuchalin A.G., Tseymakh I.Ya., Momot A.P. et al. Changes in systemic inflammatory and hemostatic responses in patients with exacerbation of chronic obstructive pulmonary disease with concomitant chronic heart failure and obesity. Pul'monologiya = Pulmonology 2014;(6):25-32. (In Russ.)

2. Zadionchenko V.C., Adasheva T.V., Lee V.V. et al. Arterial hypertension and chronic obstructive pulmonary disease - problems in the choice of therapy. Lechashchiy vrach = Doctor 2012;(7):77-81. (In Russ.)

3. Lazebnik L.B., Konev V.Yu., Efremov L.I. Polymorbidity in geriatric practice: quantitative and qualitative evaluation. Klinicheskaya gerontologiya $=$ Clinical Gerontology 2012;18(1-2):36-42. (In Russ.)

4. Dvoretskiy L.I., Chistyakova E.M. Osteoporosis in patients with COPD: comorbidity or systemic manifestation? Consilium medicum 2007;9(12):42-8. (In Russ.)

5. Belyalov F.I. Twelve theses of comorbidity. Klinicheskaya meditsina = Clinical Medicine 2009;87(12):69-71. (In Russ.)

6. Nasonov E.A., Gordeev A.V., Galushko E.A. Rheumatic diseases and multimorbidity. Terapevticheskiy arkhiv = Therapeutic Archive 2015;87(5): 4-9. (InRuss.)

7. Skotnikov A.S., Dokhova O.M., Shul'gina E.S. Place COPD in the development and progression of comorbidity. Lechashchiy vrach = Doctor 2015;(10):16. (In Russ.)

8. SmirnovA. V., ShilovE. M., Dobronravov V.A. et al. The national recommendations. Chronic kidney disease: basic principles of screening, diagnosis, prevention and treatment approaches. Nefrologiya = Nephrology 2012;16(1):85-115. (In Russ.)

9. Moe Sh.M., Roudebush V.A., Drüeke T.B. Clinical practice guidelines for the diagnosis, evaluation, prevention and treatment of mineral and bone disorders in chronic kidney disease (MKN-CKD). A brief statement by KDIGO. Nefrologiya i dializ = Nephrology and Dialysis 2011;13(1):8-12. (InRuss.)

10. Global strategy for the diagnosis, management, and prevention of chronic obstructive pulmonary disease Global 
Initiative for Chronic Obstructive Lung Disease (GOLD) 2013. Available at: http://www.goldcopd.org/.

11. Couser W.G., Remuzzi G., Mendis S. et al. The contribution of chronic kidney disease to the global burden of major noncommunicable diseases. Kidney Int 2011; 80(12):1258-70. DOI: 10.1038/ki.2011.368.

12. Drüeke T.B., Parfrey P.S. Summary of the KDIGO guideline on anemia and comment: reading between the (guide) line(s). Kidney Int 2012;82(9):952-60. DOI: 10.1038/ki.2012.270.

13. Bolotova E.V., Dudnikova A.V. Peculiarities of renal dysfunction in patients with chronic obstructive pulmonary disease. Klinicheskaya nefrologiya $=$ Clinical Nephrology 2015;(2-3):27-32. (In Russ.)

14. Vestbo J., Hurd S.S., Agustí A.G. et al. Global strategy for the diagnosis, management, and prevention of chronic obstructive pulmonary disease: GOLD executive summary. Am J Respir Crit Care Med 2013;187(4):347-65.

15. Demographic encyclopedic dictionary. Valentey D.I. Moscow: Sovetskaya entsiklopediya, 1985. (In Russ.)

16. Olenko E.S., Kodochigova A.I., Kirichuk V.F. et al. Risk factors for development of chronic kidney disease. Vestnik Tambovskogo universiteta $=$ Bulletin of the Tambov University. Series: Natural and Technical Sciences 2012;17(4):1293-9. (In Russ.)

17. Levey A.S., Stevens LA., Schmid C.H. et al. A new equation to estimate glomerular filtration rate. Ann Intern Med 2009;150(9):604-12.

18. Federal clinical recommendations on diagnostics and treatment of COPD. Russian respiratory society, 2013. Available at: http://www.pulmonology.ru/download/ COPD20142.doc. (In Russ.)
19. Chazova I.E., Chuchalin A.G., Zykov K.A., Ratova L.G. Diagnosis and treatment of patients with arterial hypertension and chronic obstructive pulmonary disease. Recommendations of Russian Medical Society on Arterial Hypertension and Russian Respiratory Society. Sistemnye gipertenzii $=$ Systemic Hypertension 2013;10(1):5-35. (In Russ.)

20. Man W.D., Kemp P., Moxham J., Polkey M.I. Skeletal muscle dysfunction in COPD: clinical and laboratory observations. Clin Sci (Lond) 2010;117(7):251-64. DOI: $10.1042 / C S 20080659$.

21. Qaseem A., Wilt T.J., Weinberger S.E. et al. Diagnosis and management of stable chronic obstructive pulmonary disease: a clinical practice guideline update from the American College of Physicians, American College of Chest Physicians, American Thoracic Society, and European Respiratory Society. Ann Intern Med 2011;155(3):179-91. DOI: 10.7326/0003-481 9-155-3-201108020-00008.

22. Mukhin N.A. Moiseev V.S., Kobalava Zh.D. et al. Cardiorenal interactions: clinical significance and role in the pathogenesis of diseases of the cardiovascular system and kidneys. Terapevticheskiy arkhiv = TherapeuticArchive 2004;76(6):39-46. (In Russ.) 